\title{
Mental toughness in surgeons: how do we measure up?
}
DB Percy ${ }^{a}$, L Streith $^{\mathrm{b}},{ }, \mathrm{CG}$ Ball ${ }^{\mathrm{b}}, \mathrm{S}$ Widder ${ }^{\mathrm{c}}, \mathrm{H}$ Wong ${ }^{\mathrm{a}}$ and $\mathrm{M}$ Hameed ${ }^{\mathrm{a}}$
a Division of General Surgery, The University of British Columbia
Division of General Surgery, The University of Calgary
Division of General Surgery, The University of Alberta
UNIVERSITY OF ALBEERTA
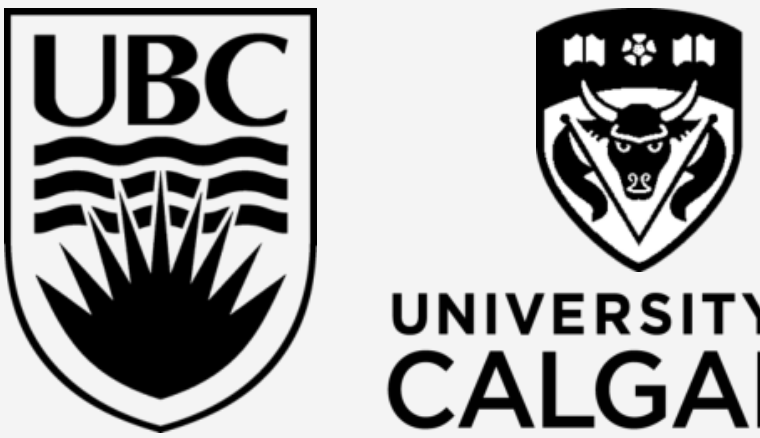
UNIVERSITY OF CALGARY

\section{Introduction}

- Mental toughness allows individuals to deal with stressful situations and perform under pressure

- It is well established in sports psychology, military and corporate training ${ }^{1}$

- There are few studies that examine mental toughness in surgeons ${ }^{2}$

- The purpose of this study wás to quantify mental toughness in general surgeons

\section{Results}

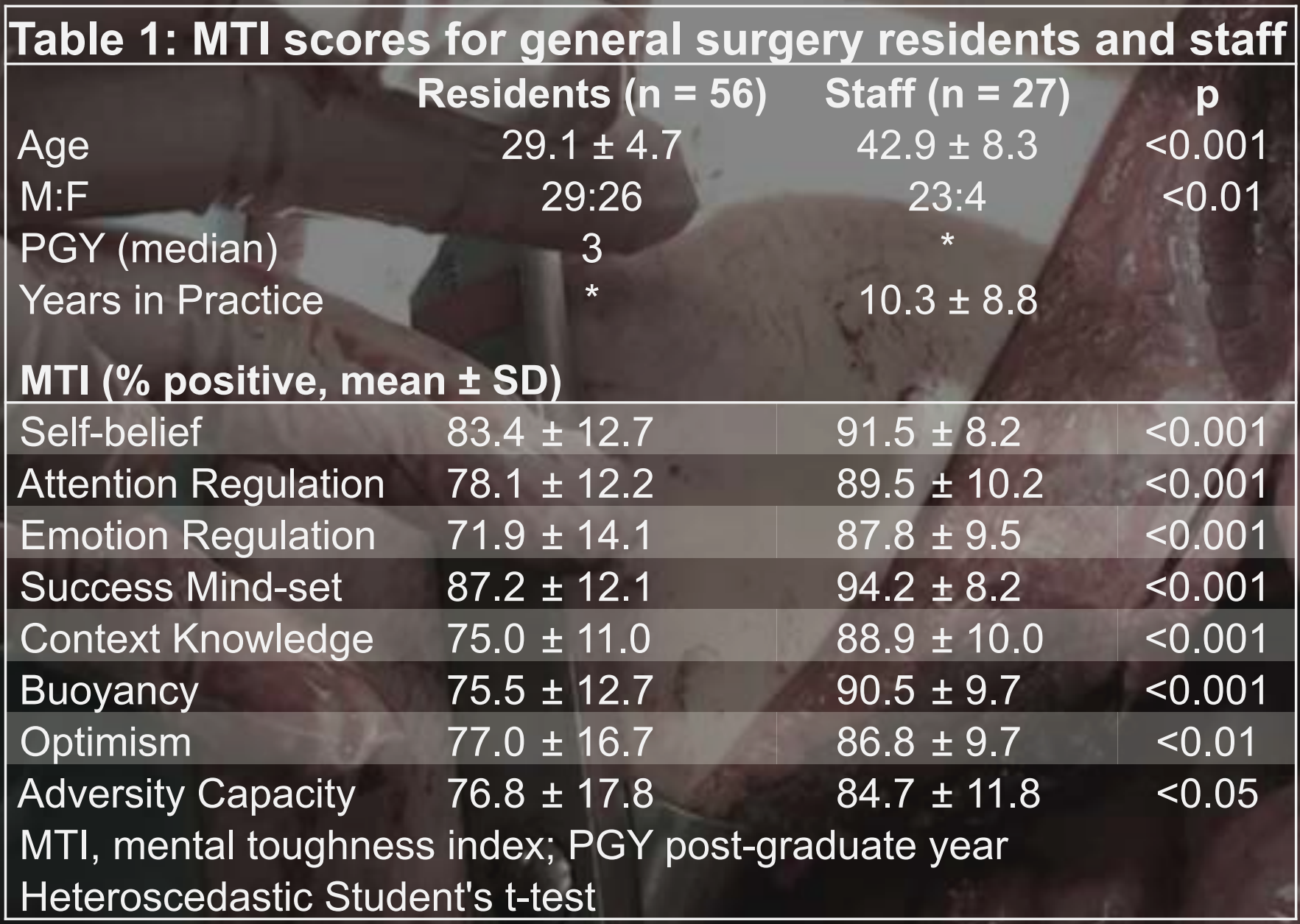

- Staff surgeons scored significantly higher than residents in all MTI domains

- Highest score was Success Mind-set for both staff and residents

- Lowest score was Emotion Regulation for residents and Capacity to Deal with Adversity for staff

- Significant difference between male and female surgeons in Attention Regulation (84.1 $111.9 \%$, $77.1 \pm 12.8 \%, p=0.02)$ and Emotion Regulation $(81.6 \pm 14.0 \%, 69.0 \pm 13.0 \%, p=0.001)$

- No significant difference in MTI scores between junior (PGY1,2) and senior (PGY-3+) residents

\section{Discussion}

- Staff age, experience may contribute to improved mental toughness, and greater use of specific techniques

- Gender, age, other experience and circumstance are potential confounders

- Mental toughness is a personality disposition, but can be developed through training ${ }^{3}$

The authors would like to acknowledge Dr. Peter Crocker for help with the Mental Toughness Index

\section{Methods}

- Online survey of University of British Columbia, University of Calgary and University of Alberta resident and staff general surgeons

- Mental Toughness Index $(\mathrm{MTI})^{1}$, validated tool measuring 8 mental toughness domains using a 7 point Liekert scale

- Additional questions examining what techniques surgeons use to help deal with stressful situations

Do you use specific techniques to deal with stressful situations?

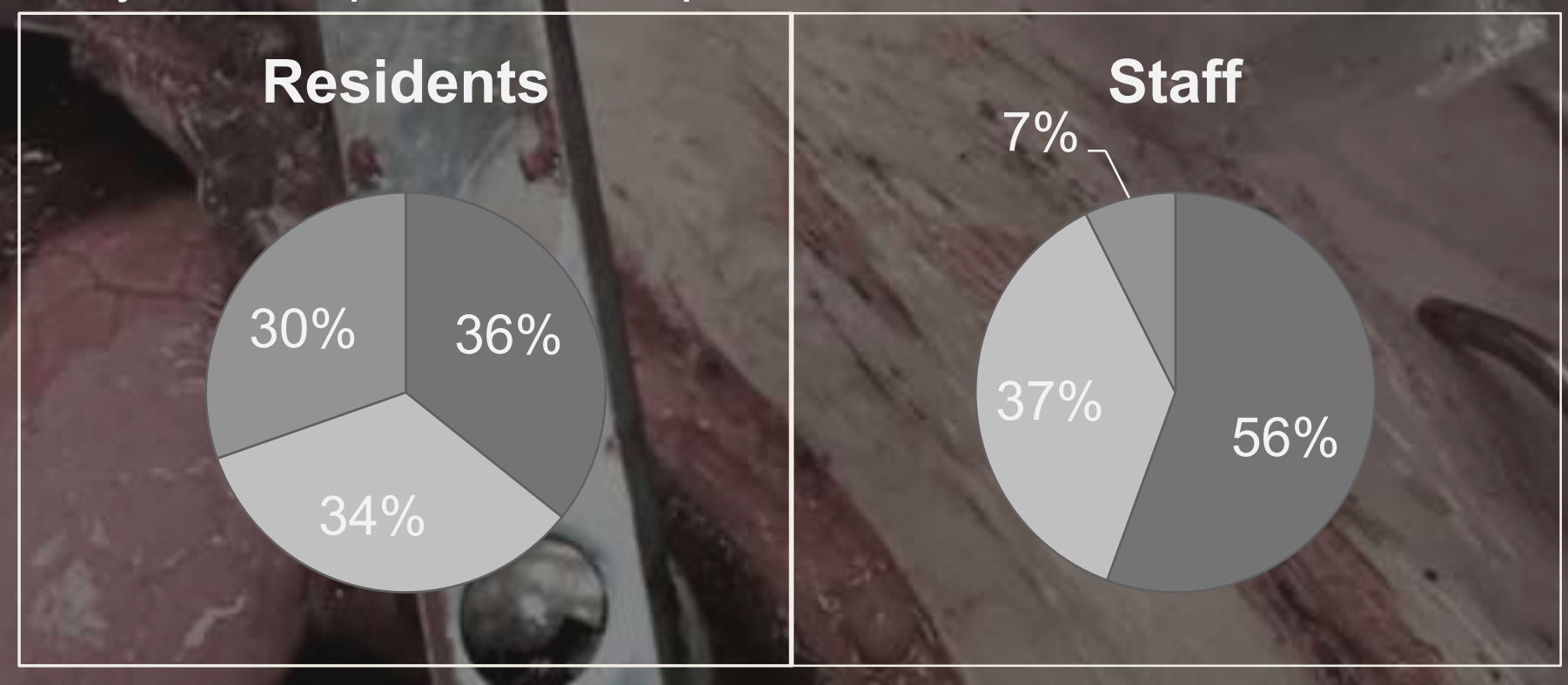

Would you be interested in additional mental toughness training?

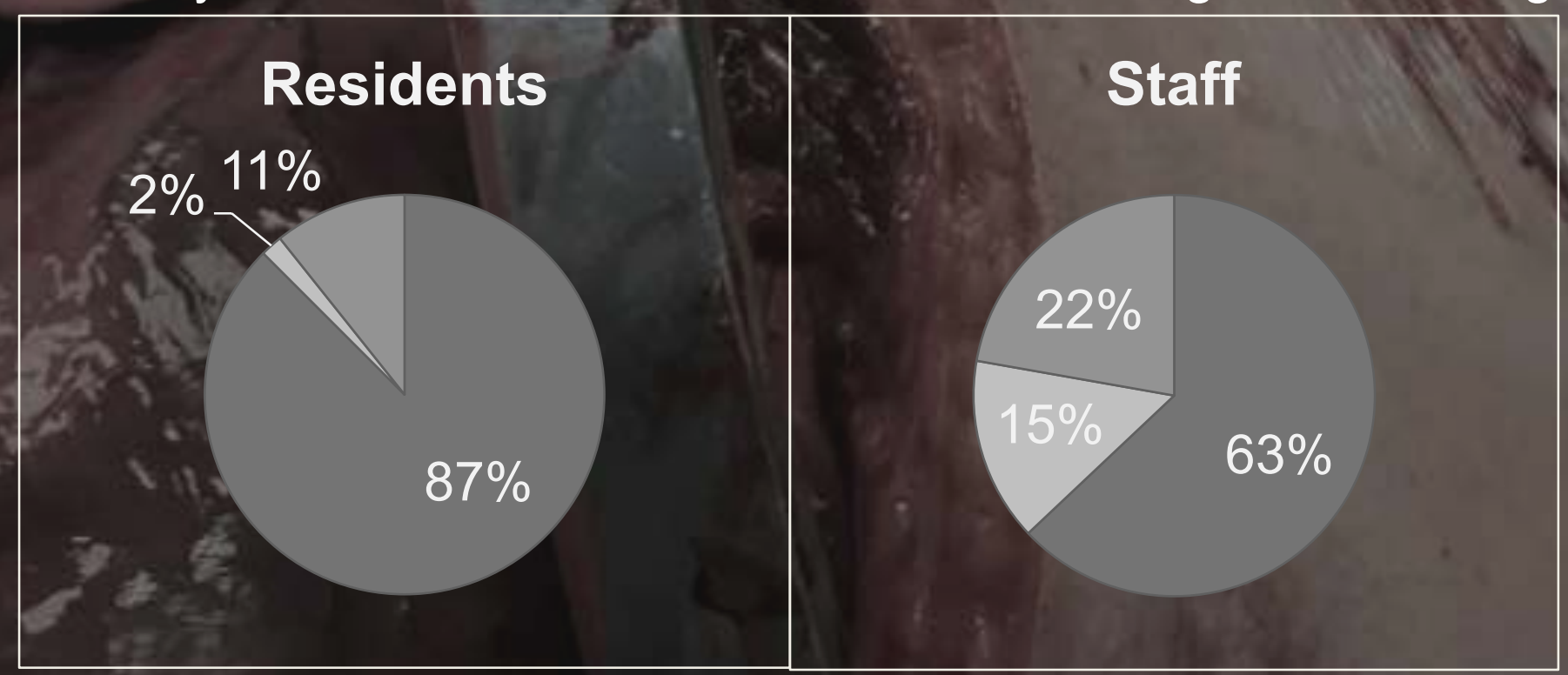

Figure 1: Mental toughness strategies $\square$ Yes $\square$ No $\square$ Uncertain

- Most common techniques included:

- Breathing, visualization, mindfulness (27\%)

- Slowing down, reframing the situation

- Staying organized, list making

\section{Conclusions}

- Staff general surgeons had significantly higher selfreported mental toughness scores than residents

- $63 \%$ of staff and $87 \%$ of residents reported interest in specific training to improve mental toughness

- There exists an opportunity to improve mental toughness in surgical residents

- Further study in development and efficacy of techniques to improve mental toughness is warranted

\section{References}

1. Gucciardi et al. J of Personality. 2014

2. Colbert et al. Br J of Oral and Maxillofacial Surgery. 2012

3. Crust. Personality and Individual Differences. 2008 